Med. Hist. (2014), vol. 58(4), pp. 519-545. (C) The Author(s) 2014. Published by Cambridge University Press 2014 This is an Open Access article, distributed under the terms of the Creative Commons Attribution licence (http://creativecommons.org/licenses/by/3.0/), which permits unrestricted re-use, distribution, and reproduction in any medium, provided the original work is properly cited.

doi: $10.1017 / \mathrm{mdh} .2014 .51$

\title{
'Shell shock' Revisited: An Examination of the Case Records of the National Hospital in London
}

\author{
STEFANIE CAROLINE LINDEN ${ }^{1 *}$ and EDGAR JONES ${ }^{2}$ \\ ${ }^{1}$ Centre for the Humanities and Health, 5th Floor, East Wing, Strand Campus, \\ King's College London, London WC2R 2LS, UK \\ ${ }^{2}$ Kings College London, King's Centre for Military Health Research, \\ Institute of Psychiatry, 16 De Crespigny Park, London SE5 8AF, UK
}

\begin{abstract}
During the First World War the National Hospital for the Paralysed and Epileptic, in Queen Square, London, then Britain's leading centre for neurology, took a key role in the treatment and understanding of shell shock. This paper explores the case notes of all 462 servicemen who were admitted with functional neurological disorders between 1914 and 1919. Many of these were severe or chronic cases referred to the National Hospital because of its acknowledged expertise and the resources it could call upon. Biographical data was collected together with accounts of the patient's military experience, his symptoms, diagnostic interpretations and treatment outcomes. Analysis of the notes showed that motor syndromes (loss of function or hyperkinesias), often combined with somato-sensory loss, were common presentations. Anxiety and depression as well as vegetative symptoms such as sweating, dizziness and palpitations were also prevalent among this patient population. Conversely, psychogenic seizures were reported much less frequently than in comparable accounts from German tertiary referral centres. As the war unfolded the number of physicians who believed that shell shock was primarily an organic disorder fell as research failed to find a pathological basis for its symptoms. However, little agreement existed among the Queen Square doctors about the fundamental nature of the disorder and it was increasingly categorised as functional disorder or hysteria.
\end{abstract}

Keywords: First World War, Trauma, Psychopathology, Case histories, Neurology, Hysteria

\section{Introduction}

Soon after the beginning of the First World War 'cases of nervous and mental shock' began to arrive in England. ${ }^{1}$ At first, the medical profession did not pay much attention to these

* Email address for correspondence: LindenS@ cardiff.ac.uk

The authors are grateful to the library and archives staff at Queen Square, in particular Louise Shepherd, Kate Brunskill and Jackie Cheshire. This work was supported by the Wellcome Trust (PhD Studentship, Centre for the Humanities and Health, King's College London).

${ }^{1}$ William Aldren Turner, 'Remarks on Cases of Nervous and Mental Shock', BMJ, 1, 2837 (1915), 833-5. 
psychological casualties which were seen as 'the more uncommon clinical products of the present war'. ${ }^{2}$ For most of 1914 , the British medical press mainly reported single cases, such as functional blindness or complete loss of memory. ${ }^{3}$ Some authors even observed a decrease in admissions to mental hospitals and interpreted this as evidence for the invigorating powers of warfare:

It is not the great tragedies of life that sap the forces of the brain and wreck the psychic organism. On the contrary, it is small worries, the deadly monotony of a narrow and circumscribed existence, the dull drab of a life without joy and barren of an achievement, the self-centred anaemic consciousness, it is these experiences that weaken and diminish personality and so leave it a prey to inherited predispositions or to the slings and arrows of outrageous fortune. ${ }^{4}$

Yet, advocates of the beneficial effects of war on mental health were soon faced with evidence that challenged their position. On 12 December 1914, the British Medical Journal had published an article by T.R. Elliott on a surprising number of functional paralyses following shell explosions. Consultant physician to the British Army in France, he acknowledged that these disorders were often difficult to distinguish from those caused by brain lesions. In addition, Elliott believed that they assumed diverse forms: 'the man may become blind, or deaf, or dumb; he may be seized by a violent and coarse tremor that shakes his body for days; or he may be paralysed with a hemiplegia or paraplegia' 5 Although these soldiers did not show any obvious physical injuries, the proximity to explosions was seen as the decisive causative factor and from the winter of 1914/15 onwards they were increasingly labelled as 'shell shock'. ${ }^{6}$

The term found its way into medical terminology from the everyday language of soldiers in the trenches. Prominently featured in a Lancet paper by the Cambridge medical psychologist Charles Samuel Myers (1873-1946) in February 1915, ${ }^{7}$ the diagnosis became popular in the first half of the war but - following a recommendation by Myers was subject to restricted use in official terminology in $1917 .^{8}$ Army doctors were then instructed to label suspected mental cases as 'Not Yet Diagnosed (Nervous)' (NYDN) until they were assessed by a specialist. ${ }^{9}$ The relative contribution of organic and psychological processes to the syndromes of shell shock and the NYDN category remained a matter of ongoing debate in the British medical literature into the 1920s.

The diagnosis of shell shock was not purely a medical issue but also a product of the interplay between soldiers' experiences of war, the interpretations of physicians and official attitudes. ${ }^{10}$ Historians of medicine have often viewed the disorder in cultural terms

2 Ibid., 833; From a Special Correspondent in Northern France, 'Medical Arrangements of the British Expeditionary Force', BMJ, 2, 2815 (1914), 1037-8.

${ }^{3}$ Medical Society of London, 'Surgical Experiences of the Present War: Functional Blindness', BMJ, 2, 2813 (1914), 938-42; 2nd Eastern General Hospital, 'Home Hospitals and the War: Complete Loss of Memory', BMJ, 2, 2814 (1914), 992.

4 Saturday, September 4, 1915, 'Insanity and the War', The Lancet, 186, 4801 (1915), 553-4. Author cites Eighty-fifth Annual Report of the Belfast District Lunatic Asylum.

5 T.R. Elliott, 'Transient Paraplegia from Shell Explosions', BMJ, 2, 2815 (1914), 1005-6: 1006.

6 Turner, op. cit. (note 1), 833-5.

${ }^{7}$ Charles Samuel Myers, 'A Contribution to the Study of Shell Shock', The Lancet, 185, 4772 (1915), 316-20. On the introduction of the term 'shell shock' see also Edgar Jones and Simon Wessely, Shell Shock to PTSD: Military Psychiatry from 1900 to the Gulf War (Hove: Psychology Press, 2005), 21.

${ }^{8}$ Charles Samuel Myers, Shell Shock in France, 1914-1918 (Cambridge: Cambridge University Press, 2011, 1940), 98.

${ }^{9}$ Arthur Frederick Hurst, 'Observations on the Aetiology and Treatment of War Neuroses', BMJ, 2, 2961 (1917), 409-14.

10 Jessica Meyer, 'Separating the Men from the Boys: Masculinity and Maturity in Understandings of Shell Shock in Britain', Twentieth Century British History, 20, 1 (2009), 1-22. 
seeking to interpret the meaning of symptoms and the function that they performed for both the patient and the clinician. Tracey Loughran, for example, has argued convincingly that shell shock has to be analysed in terms of the concerns, knowledge and practices of both patients and doctors. ${ }^{11}$ In addition, she emphasised how models of shell shock and its causation drew on pre-war concepts of mental health. ${ }^{12}$ Ben Shephard demonstrated that shell shock played a significant role in the British Army's attempts to understand breakdown and to find ways of accommodating the psychological casualty without branding him a coward or weakening the resolve of his comrades. ${ }^{13}$ Peter Barham made extensive use of hospital records and war pension files in his analysis of the treatment of servicemen who suffered from mental illness during the First World War. He argued that the asylum partly served as a repository for 'inefficient' soldiers who could not cope with the adverse conditions at the front line and were therefore a hazard in the army. ${ }^{14}$ Although Hans Binneveld drew extensively on reports of British, French and German soldiers who had broken down in combat, he did not have a clinical series on which to base an analysis of symptoms and interpretations. Drawing on war pension files and personal narratives, Fiona Reid's study of ex-servicemen explored enduring symptoms experienced by discharged soldiers attempting to reintegrate themselves within their families and the workplace. ${ }^{15}$

Based on a review of the considerable number of articles and monographs on shell shock that appeared in Britain between 1915 and 1920, Leese, Shephard and Binneveld are in general agreement that aetiological models in Britain shifted from an earlier emphasis on organic causes to a growing recognition of the importance of psychological processes. ${ }^{16}$ Although aetiological concepts and treatment approaches have been a major focus of modern scholarly analysis, the systematic study of the psychopathology of shell shock has been comparatively neglected. Modern assessment of its clinical form is mainly based on case reports published in the medical press during the war. ${ }^{17}$ Doctors, who sought to establish a name for themselves, often focused on the most dramatic clinical presentations, such as functional movement disorders, muteness and deafness. As result, the reader of the medical literature of the time only catches a glimpse of the great variety of symptoms that could be provoked by the intense stress of combat.

To date, few scholars have studied original case records. Petra Peckl analysed a large number of original medical case records held at the Freiburg Military Archives. These records from various German military hospitals of the First World War not only illustrate treatment practices of individual institutions but also clarify referral paths and treatment networks for psychologically injured soldiers in wartime Germany. Peckl emphasises the

11 Tracey Loughran, 'Shell Shock, Trauma, and the First World War: The Making of a Diagnosis and its Histories', Journal of the History of Medicine and Allied Sciences, 67, 1 (2012), 94-119.

12 Tracey Loughran, 'Shell Shock and British Psychological Medicine', Social History of Medicine, 22 (2009), 79-95.

${ }^{13}$ Ben Shephard, A War of Nerves: Soldiers and Psychiatrists in the Twentieth Century (Cambridge, MA: Harvard University Press, 2001).

${ }^{14}$ Peter Barham, Forgotten Lunatics of the Great War (New Haven, CT: Yale University Press, 2004), 23: 26.

15 Fiona Reid, Broken Men: Shell Shock, Treatment and Recovery in Britain 1914-1930 (London: Continuum International Publishing Group, 2010), 41-61 [Paperback version, 2011].

16 Peter Leese, Shell Shock: Traumatic Neurosis and the British Soldiers of the First World War (New York: Palgrave, 2002), 60; Hans Binneveld, From Shell Shock to Combat Stress: A Comparative History of Military Psychiatry (Amsterdam: Amsterdam University Press, 1997), 86-7; Shephard, op. cit. (note 13), 31.

17 Binneveld, op. cit. (note 16), 84-5; Binneveld cites Myers's case histories published in the Lancet: Charles Samuel Myers, 'Contributions to the Study of Shell Shock: Being an Account of Certain Cases Treated by Hypnosis', The Lancet, 190, 4819 (1916), 65-9; for the First World War case reports also see Shephard, op. cit. (note 13), eg. the chapter 'Psychiatry at the Front, 1917-18', 53-71. 
importance of patient records as a source for historical research because they 'show a much more complex image of the psychological disorders of soldiers in the First World War than that reflected by the lofty impressions provided in the medical literature'. However, Peckl argues that 'expectations that patient perspectives might be reconstructed from medical records have proven rather too optimistic'. ${ }^{18}$

British medical records have been analysed by Peter Leese, who researched three groups of patient notes: those treated at Queen Square, the representative sample collected in the immediate aftermath of the war by the MRC and British Museum and now held at the National Archives, and 111 officer case notes from the Lennel Convalescent Home held in the National Archives of Scotland. ${ }^{19}$ He classified 57 shell shock cases held at the National Archives (TNA) according to severity of symptoms, dividing these cases into three groups with 'slight', 'borderline' and 'acute' symptoms, but did not provide a systematic analysis of their psychopathology. As Leese acknowledged, the selection criteria employed by the Medical Research Council (MRC) and the British Museum resulted in the sample being 'heavily skewed towards the early part of the war'. Having excluded cases with incomplete records, he concluded that 'these notes cannot claim to be a representative sample'. ${ }^{20}$ Nevertheless, this remains an important attempt to engage with clinical material and tie practice to contemporary publications. A strength of the TNA sample is that it includes patient records from general hospitals and thus provides insight into the presentation and treatment of traumatised soldiers outside specialised units.

Original case records are also available for the two main Canadian military hospitals in Britain that specialised in the treatment of shell shock cases, the Granville Special Hospital at Ramsgate and the Buxton Red Cross Special Hospital. ${ }^{21}$ Based on their analysis of admission and discharge books and randomly selected case records, Humphries and Kurchinksi concluded that neither diagnostic labels - in particular 'neurasthenia' and 'hysteria' - nor treatment methods were linked to the patient's social class. ${ }^{22}$ The authors also emphasised the importance of research into original case records in order to challenge the stereotypes that have become pervasive in both the scholarly and popular literature on the First World War. For example, they found that their data called for a revision of a 'binary [treatment] model of discipline and analysis'. This accords with our analysis of British ${ }^{23}$ and German ${ }^{24}$ treatment practice, which was far more varied and complex than such dichotomous labels would suggest. Although medical records inevitably reflect the biases of the respective institutions and their practitioners they are crucial sources for actual practices and attitudes in the treatment institutions. Ideally their physiciancentred accounts would be complemented by original statements from the soldier-patients themselves, of which some can be found in the records as well.

\footnotetext{
18 Petra Peckl, 'What the patient records reveal: reassuring the treatment of "war neurotics" in Germany (19141918)', in Hans-Georg Hofer, Cay-Ruediger Pruell and Wolfgang U. Eckart (eds), War, Trauma and Medicine in Germany and Central Europe (1914-1939) (Freiburg: Centaurus, 2011), 148.

${ }^{19}$ Leese, op. cit. (note 16), 76-80, 90, 108-12.

20 Ibid., 91.

${ }^{21}$ Mark Osborne Humphries and Kellen Kurchinski, 'Rest, Relax and Get Well: A Re-Conceptualisation of Great War Shell Shock Treatment', War \& Society, 27, 2 (2008), 89-110.

22 Ibid., 95.

23 Stefanie Caroline Linden, Edgar Jones and Andrew J. Lees, 'Shell Shock at Queen Square: Lewis Yealland 100 Years On', Brain, 136, 6 (2013), 1976-88.

${ }^{24}$ Stefanie Caroline Linden and Edgar Jones, 'German Battle Casualties: The Treatment of Functional Somatic Disorders During World War One', Journal of the History of Medicine and Allied Sciences, 68 (2013), 627-58.
} 
War pension files have been used to explore the psychopathology of post-combat syndromes. ${ }^{25}$ From the 22756 war pension files held at TNA, two hundred cases of shell shock were randomly selected, together with two hundred cases of disordered action of the heart (DAH) and 167 cases of servicemen who had been gassed without permanent organic injury. These data were analysed in the context of a study that compared symptom profiles across different military conflicts. Although war pension records contain detailed clinical descriptions of traumatised soldiers over time, they are biased towards severe and chronic cases. As a consequence, there remains uncertainty about the acute clinical presentation of shell-shocked British soldiers during the conflict itself. Our analysis is based on the original records of all 462 soldiers with functional disorders (that is without any demonstrable organic signs) treated at the National Hospital from August 1914 to the end of 1919. These documents show us how a sub-population of British soldiers, who were referred to the UK for specialist treatment, presented clinically. The series also sheds light on British neurologists' attitude towards shell shock, their interpretation of symptoms and the resulting treatment approaches. This paper focuses on the clinical presentations. We have previously reviewed the ideas and practices of one of the National Hospital's most active junior doctors, Lewis Ralph Yealland (1884-1954). ${ }^{26}$

Elaine Showalter, in the The Female Malady, and Pat Barker, in her novel Regeneration have created the impression that punishment was the hallmark treatment of Queen Square physicians. ${ }^{27}$ We have highlighted their misconceptions about Yealland's work in a recent paper. ${ }^{28}$ Showalter's claim that Yealland was 'probably the most extreme advocate of disciplinary treatment among the English doctors" ${ }^{29}$ is not borne out by the medical records. Treatment at Queen Square generally included the whole spectrum of procedures available at the time apart from psychoanalysis, and Yealland only resorted to painful strong currents if the patient did not respond to first-line treatment.

With 30780 beds for other ranks and 5,884 beds for officers, London provided a little over $10 \%$ of the total UK hospital beds for military use in 1918 and almost $31 \%$ of the total of beds for officers. ${ }^{30}$ The National Hospital for the Paralysed and Epileptic (today called the National Hospital for Neurology and Neurosurgery) at Queen Square in the heart of London admitted a large number of soldiers with physical injuries, such as gunshot wounds affecting the peripheral or central nervous system or serious head traumas. Yet, Queen Square also ranked among the most important centres for the treatment of shell shock cases, the equal of Maghull, the Maudsley and Craiglockart. ${ }^{31}$ While funding and staff limitations forced many general hospitals to conduct low-cost mass treatments that required minimal input from qualified personnel, the National Hospital had specialist staff,

${ }^{25}$ Edgar Jones et al., 'Post-Combat Syndromes from the Boer War to the Gulf War: A Cluster Analysis of Their Nature and Attribution', BMJ, 324, 7333 (2002), 321-4.

${ }^{26}$ Linden, Jones and Lees, op. cit. (note 23).

${ }^{27}$ Elaine Showalter, The Female Malady: Women, Madness and English Culture 1830-1980 (London: Virago, 1987), 178; Pat Barker, Regeneration (London: Penguin, 2008).

${ }^{28}$ Linden, Jones and Lees, op. cit. (note 23).

${ }^{29}$ Showalter, op. cit. (note 27), 176-8.

30 Jay Winter and Jean-Louis Robert, Capital Cities at War: Paris, London, Berlin 1914-1919 (Cambridge: Cambridge University Press, 1997).

${ }^{31}$ Mark S. Micale and Paul Frederick Lerner, Traumatic Pasts: History, Psychiatry, and Trauma in the Modern Age, 1870-1930, Cambridge Studies in the History of Medicine (Cambridge: Cambridge University Press, 2001); Edgar Jones, 'Shell Shock at Maghull and the Maudsley: Models of Psychological Medicine in the UK', Journal of the History of Medicine and Allied Sciences, 65, 3 (2010), 368-95. 
extensive treatment and research facilities and less pressure to discharge patients within short periods of time. ${ }^{32}$

The National Hospital mainly received referrals from other military hospitals, such as the Fulham Military Hospital and the First London General Hospital at Camberwell. Some patients were transferred from the two official clearing hospitals, D Block at the Royal Victoria Hospital, Netley and the Maudsley wing of the Fourth London General Hospital at Denmark Hill. Eleven per cent of soldiers with functional disorders were direct referrals from the Western front. With only 100 military beds in 1915, Queen Square operated on a much smaller scale than the specialist treatment hospital Maghull, which had 300 beds, rising to 500 in the second half of the war. ${ }^{33}$ However, by the beginning of the First World War, Queen Square had gained an international reputation for the treatment of neurological disorders and had pioneered neurosurgery in England. Contemporaries referred to Queen Square as 'the temple of British neurology' and compared its staff to 'a priesthood for the spread of the neurological faith of Britain'. ${ }^{34}$ Furthermore, although its proportion of military beds (100 out of over 300000 ) in the UK was exceedingly small, the National Hospital did attract a relatively high number of patients with functional neurological disorders (over 400 out of the estimated 80000 overall number of 'shell shock' patients).

In his monograph on shell shock, Peter Leese has stressed the uniqueness of the Queen Square case records as 'the most detailed source we have from a single hospital treating shell shock cases during the war'. ${ }^{35}$ However, Leese believed that the case records were incomplete. In particular, Lewis Yealland's case files were thought to be missing, and he only identified two hundred military cases treated at the National Hospital between 1915 and $1924 .^{36}$ A new search of the archives has shown that the actual numbers were much higher (see below).

Shephard has stressed that the study of case records and medical publications inevitably 'contains an inherent source-bias'. The reader is presented with the doctor's perspective and the patient's voice is rarely heard in an unfiltered way. ${ }^{37}$ Therefore the study of medical records should be complemented with patient views. The patient histories in the Queen Square records always contained verbatim quotes from the soldiers and - in a very few cases - handwritten reports or resumes by the patient.

\section{The National Hospital: Neurologists Encounter Shell Shock}

By 1914, the National Hospital for the Paralysed and Epileptic had gained an international reputation for the treatment of neurological disorders and neurosurgery, ${ }^{38}$ so it was scarcely surprising that severe or challenging military cases were referred there from France. As early as October 1914, two British soldiers arrived. They were suffering from 'GPI' (General Paralysis of the Insane), an advanced state of syphilis. In early November, the first soldiers with injuries to peripheral nerves and the spinal cord were

\footnotetext{
32 Ibid., 213-14.

${ }^{33}$ For a detailed account of the treatment at Maghull during World War One see Jones, op. cit. (note 31). Patient statistics and the number of military beds can be found in The National Hospital, Report for the year ending 31 December 1914, Queen Square Archive.

34 W.J.M.A. Maloney, 'Obituary: “The National” and Dr F.E. Batten', Journal of Nervous and Mental Disease, 49 (1919), 91-4.

35 Leese, op. cit. (note 16), 77.

${ }^{36}$ Leese, op. cit. (note 16), 75; also: Micale and Lerner, op. cit. (note 31), 217.

${ }^{37}$ Shephard, op. cit. (note 13), XXIII.

${ }^{38}$ Gordon Holmes, The National Hospital, Queen Square, 1860-1948 (Edinburgh: E. \& S. Livingstone, 1954).
} 


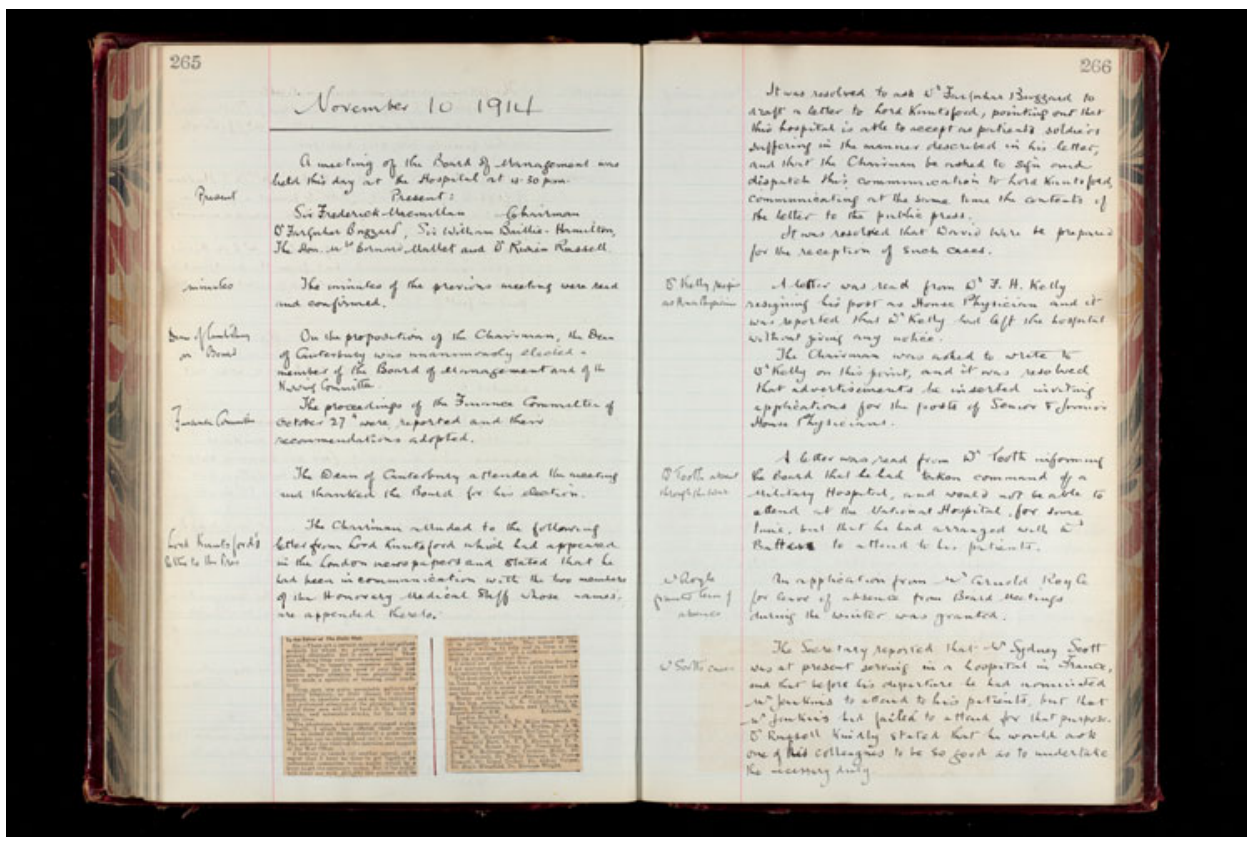

Figure 1: Minutes from the Board of Management meeting, 10 November 1914, Queen Square Archives; appended to the minutes is an article by Lord Knutsford: 'To the editor of the Daily Mail' (exact date unknown).

admitted. However, the hospital was soon to be made aware of the problem of 'nervous and mental shock'. At its meeting on 10 November 1914 the Hospital's Board of Management discussed an appeal from Lord Knutsford, Chairman of the London Hospital House Committee, that had been published in the London newspapers (see Figure 1):

There are a certain number of our gallant soldiers for whom no proper provision is at present obtainable but is sorely needed. They are suffering from very severe mental and nervous shock due to exposure, excessive strain, and tension. They can be cured if only they receive proper attention from physicians who have made a specialty of treating such conditions. These men are quite unsuitable patients for general hospitals, as their chance of recovery depends on absolute quiet and on the individual and prolonged attention of the physician. If not cured, these men will drift back to the world as wrecks, and miserable wrecks, for the rest of their lives. ${ }^{39}$

James Collier and William Aldren Turner, two consultants from the National Hospital had already offered their support to the War Office. It was decided that Farquhar Buzzard, another consultant neurologist at Queen Square, would draft a letter to Lord Knutsford and the press, pointing out that the National Hospital would accept soldiers with mental and nervous affections. 'David Wire', one of the hospital wards, was prepared for the reception of such cases and the War Office informed that wounded soldiers, suffering from any nervous ailment were eligible for admission. ${ }^{40}$

On 14 November 1914, a soldier was admitted with neurological symptoms that could not be attributed to an organic lesion: Adolf S., a 22-year-old Belgian unable to move

39 Lord Knutsford, 'To the editor of the Daily Mail', Daily Mail (exact date unknown), newspaper cutting appended to the Minutes from the Board of Management meeting, 10 November 1914, Queen Square Archive (see Figure 1).

${ }^{40}$ Minutes from the Board of Management meeting, 10 November 1914, Queen Square Archive (see Figure 1). 
his legs. Two more soldiers with unexplained neurological symptoms arrived at Queen Square on 8 December 1914. Walter E., a 23-year-old private from the First Royal Dragoons, suffered from weakness and 'violent trembling' of his legs. The other soldier was Steward B., an 18-year-old private of the London Scottish Regiment, who had been sent to the front in mid-October. The case record reads:

The life in the trenches was very hard. There was considerable rain. They were not able to get water. The diet consisted of 'bully beef', jam, cheese and bread. The sand would come into the food and this increased the thirst. They had little chance to sleep, the eye-strain was very severe. Patient had a great deal to do with handling wounded and dying soldiers which made a deep impression on him. The first day he was in a trench, he had in his line of vision a pile of corpses one of which had the face turned toward him and appeared to be sleeping this made such an impression upon him that he cannot free himself of this vision.

Just before being sent home, he was five days and six nights in the trenches at a stretch under the above conditions. The noises made by shells and the uncertainty of where they would strike caused great uneasiness and strain. Patient's comrades remarked that he did not answer when they spoke to him and appeared not to realize that they were speaking to him. Of this he knew nothing until told later on. He could not hold his weapon properly, nor shoot accurately. He was very shaky. Suffered much from headache. He was sent away from trenches November 14 and arrived at Southampton November 21.41

The physical examination did not reveal any abnormalities; a 'considerable improvement' was achieved through massages and pain medication. ${ }^{42}$

The numbers of soldier-patients admitted to Queen Square increased rapidly after William Aldren Turner (1864-1945), who had recently returned from duty in France, wrote a letter to the Chairman of the hospital on 21 December 1914 suggesting that one or two wards be set apart entirely for the treatment of military patients suffering from nervous shock. From mid-January 1915, one ward of sixteen beds was provided for servicemen and arrangements were made to prepare a second ward, which was only finally approved in November $1915 .{ }^{43}$ In total, four wards (David Wire, John Back, Morgan and Princess Christian), a third of the hospital, were eventually allotted to military casualties, together with two adjoining houses in Queen Square (Annex 12a and 12b) to accommodate between thirty and forty men. ${ }^{44}$ By the end of the war the National had about one hundred beds for wounded servicemen.

Although the hospital opened its doors to casualties from France, its capacity to treat patients was initially undermined by the loss of experienced staff who had volunteered for military service. ${ }^{45}$ Increasingly junior medical posts were filled by female doctors and retired consultants who returned to take up clinical duties. ${ }^{46}$ Later in the war, demands on the clinical staff were intensified by a request from the Ministry of Pensions to hold special out-patient sessions for wounded servicemen. The high numbers of military casualties led to longer waiting lists for civilian patients and "complaints by the medical staff that

${ }^{41}$ Steward B., Queen Square Records, Dr Batten, 1915, Queen Square Archive; the pain medication was 'aspirin'. 42 Ibid.

43 Minutes from the Board of Management meeting, 12 January 1915 and 9 November 1915, Queen Square Archive.

${ }^{44}$ Holmes, op. cit. (note 38), 58-9.

45 Minutes from the Board of Management meeting, 10 November 1914, Queen Square Archive: Howard Henry Tooth (1856-1925), consultant neurologist at Queen Square since 1887, informed the Board in writing that he had taken command of a military hospital and would not be able to attend to his duties at the National Hospital for some time. Also: Minutes from the Board of Management meeting, 12 January 1915, Queen Square Archive: Absence of W. Aldren Turner (1864-1945): 'A letter was read from Dr Aldren Turner that he had been called away to France for a period of about two months ...'.

46 Minutes from the Board of Management meeting, 10 November 1914, Queen Square Archive: Frederick Eustace Batten (1866-1918), Dean of the National's Medical School who had resigned from his clinical duties in 1909 , took responsibility for Tooth's patients in his absence. 
frequently there was no accommodation even for persons who were seriously ill and urgently required indoor treatment', ${ }^{47}$

Between 3 August 1914 and 31 December 1919, 1212 soldiers were treated at the National Hospital, accounting for $45 \%$ of all male admissions. For 462 soldiers, $38 \%$ of all military admissions, doctors could find no identifiable organic pathology. The Queen Square neurologists mainly classified such cases as 'functional disorder', 'hysteria', 'neurasthenia' 'neurosis' and 'shell shock' (see Table 1). Consultants did not differ markedly in their preferences of diagnostic labels. Although as a group they were fairly consistent in the diagnostic terms they used, their preferences changed over time. These changes in diagnostic labelling mirrored the evolving aetiological models for disorders without clearly defined organic changes. The ideologically charged diagnosis of "traumatic neurosis' indicating an organic aetiology was mainly used at the beginning of the war (ten cases in 1915). ${ }^{48}$ Similarly, 'shell shock' was employed as a diagnostic label in the first half of the war (one case in 1915, thirty cases in 1916) and was very rarely used afterwards (only two cases in 1917/8 respectively), in accordance with the official restriction on the use of the term. Both 'neurasthenia' and 'neurosis', very common in the first two years of the conflict, virtually disappeared as diagnoses in the second half of the war. Interestingly, 'hysteria' was resurrected as a diagnostic term by Queen Square neurologists during 1918, after it had almost been abandoned in 1915. In general, however, Queen Square physicians preferred the more descriptive diagnosis of a 'functional disorder' over aetiologically biased terms such as 'shell shock' or 'hysteria', although the 'functional disorder' category decreased in favour of the hysteria diagnosis in 1918.

Table 1 records the consultants responsible for treating these cases. Principal among the consultants were Howard H. Tooth, James Collier, James Taylor, W. Aldren Turner, J.S. Risien Russell, Edward Farquhar Buzzard and Frederick Eustace Batten (see Figure 2). The common feature of nearly two hundred cases was Lewis Ralph Yealland who as a junior medical officer was responsible for the daily care and treatment of servicemen. ${ }^{49}$

Dr James Taylor (1859-1946), who had worked as a businessman before studying medicine, was a member of the Hospital's Board of Management and had additional appointments in the Royal London Ophthalmic Hospital and the Queen's Hospital for Children. ${ }^{50}$ The reminiscences of one of his later junior doctors, J. Purdon Martin, are an instructive account of the major achievements of the consultants and working atmosphere at the National Hospital. ${ }^{51}$ Farquhar Buzzard (1871-1945), appointed consultant physician in 1905, resigned from the National Hospital in 1921 to move to a post at St Thomas's and in 1928 became Regius Professor of Medicine at Oxford. Collier (1870-1935), who introduced the term 'motor neuron disease', was well known for his stimulating teaching

\footnotetext{
${ }^{47}$ Holmes, op. cit. (note 38), 59.

48 The term 'traumatic neurosis' is closely linked to Hermann Oppenheim's trauma concept where organic microlesions caused by shell explosions were in the heart of the aetiological illness model; this was very similar to Mott's organic illness model, as cited in Frederick Walker Mott, War Neuroses and Shell Shock (London: Oxford University Press, 1919), 41. Queen Square neurologists used the term in cases they believed to have an organic origin.

49 For a detailed account of Yealland's life and work at Queen Square, see Linden, Jones and Lees, op. cit. (note 23).

${ }^{50}$ Holmes, op. cit. (note 38), 62.

51 James Purdon Martin, 'Reminiscences of Queen Square', BMJ (Clinical Research Edn), 283, 6307 (1981), $1640-2$.
} 
Number of cases/Consultant

RMO (junior doctor)

Military rank

Average age [years]

Duration of symptoms [weeks]

Length of stay at QS [days]

Nationality

Year of admission

Marital status

Referred from

Wounded in battle

Exposed to front-line service

Past history of mental problems

Family history of mental illness

Contemporaneous diagnosis*
$N=462$

Dr Tooth: 84

Dr Collier: 78

Dr Taylor: 71

Dr Turner: 55

Dr Russell: 52

Dr Buzzard: 32

Dr Batten: 32

Dr Wilson: 21

Dr Howell: 14

Dr Steward: 12

Dr Holmes: 7

Dr Saunders: 4

Yealland: 196

Walshe: 45

Adrian: 14

Privates: $382(83 \%)$

NCOs: $76(16 \%)$

Officers: $4(1 \%)$

$27.8 \pm 7.5$

$37.7 \pm 70.82$

$69.34 \pm 61.6$

British: 411

Irish: 19

Belgian: 13

Canadian: 9

Australian: 9

South African: 1

1914: 5

1915: 122

1916: 121

1917: 94

1918: 87

1919: 33

Married: 281

Single: 181

British hospital/home: 204

Front line (Hospital): 53

$$
\begin{aligned}
& N=119 \\
& N=433 \\
& N=23 \\
& N=22
\end{aligned}
$$

Functional disorder: 166

Neurasthenia: 76

Hysteria: 85

Neurosis: 61

Shell shock: 32

Traumatic neurosis/concussion: 15

Psychasthenia: 7

Dementia praecox: 8

Depression: 3

(Exhaustion psychosis): 5

Reflex nervous disorder: 2

Malingering: 2

Table 1: Continued on next page. 
Symptoms*

Result of treatment (as indicated in notes)

Recommendation for 'Fitness for military service'

Treatment
Involuntary movements (shaking, tremor, choreatic movements, abnormal gait etc.): 85

Visual disturbance (blindness, diplopia etc.): 10

Deafness: 11

Motor disturbances other than involuntary

movements: 201

Somato-sensory disturbance: 139

Speech disturbances (aphonia, stutter etc.): 65

Pseudo-seizures: 34

Anxiety and depression: 98

Dissociative states: 17

Catatonic symptoms: 6

Pain and autonomic dysfunction: 105

Psychotic symptoms: 5

Cured: 186 ,

Improved: 212,

In status quo: 60

Worse: 4

Active service: 3 ,

Home service: 41,

Garrison service: 1 ,

Discharge, 'no further use': 64,

Furlough and duty: 11,

Furlough and light duty: 38,

Already discharged from military service: 57

Faradism: 191 (commonly combined with re-education and suggestion),

Isolation: 44

Physical treatment (massage, baths, heat etc.): 189 ,

Exercises: 100,

Persuasion: 5

* One patient can have several diagnoses and symptoms from several symptom groups.

Table 1: Clinical and socio-demographic characteristics of all soldiers with functional symptoms admitted to the National Hospital from August 1914 to the end of 1919.

sessions 'with just enough sense of drama and the histrionic'. ${ }^{52}$ J.S. Risien Russell (1864-1939), born in British Guiana, also known as an inspiring teacher, took an active part in the campaign for the deinstitutionalisation of mental disorders and became Chairman of the National Society for Lunacy Reform. ${ }^{53} \mathrm{He}$ was the first physician at Queen Square to introduce the malarial treatment of general paralysis. ${ }^{54}$ Unlike Russell, who was particularly interested in mental disorders, Gordon Holmes (1876-1965) was a 'pure neurologist' 55 and with his thorough scientific approach 'apt to forget that he was dealing with flesh and blood' ${ }^{56}$ Being based at military hospitals in France throughout the war, he only treated four soldiers with functional neurological symptoms at Queen Square,

52 Ibid., 1641.

53 Walter John O'Connor, British Physiologists, 1885-1914: A Biographical Dictionary (Manchester: Manchester University Press, 1991), 493.

54 Martin, op. cit. (note 51), 1641.

55 Myers, op. cit. (note 8), 20.

56 Martin, op. cit. (note 51), 1641. 


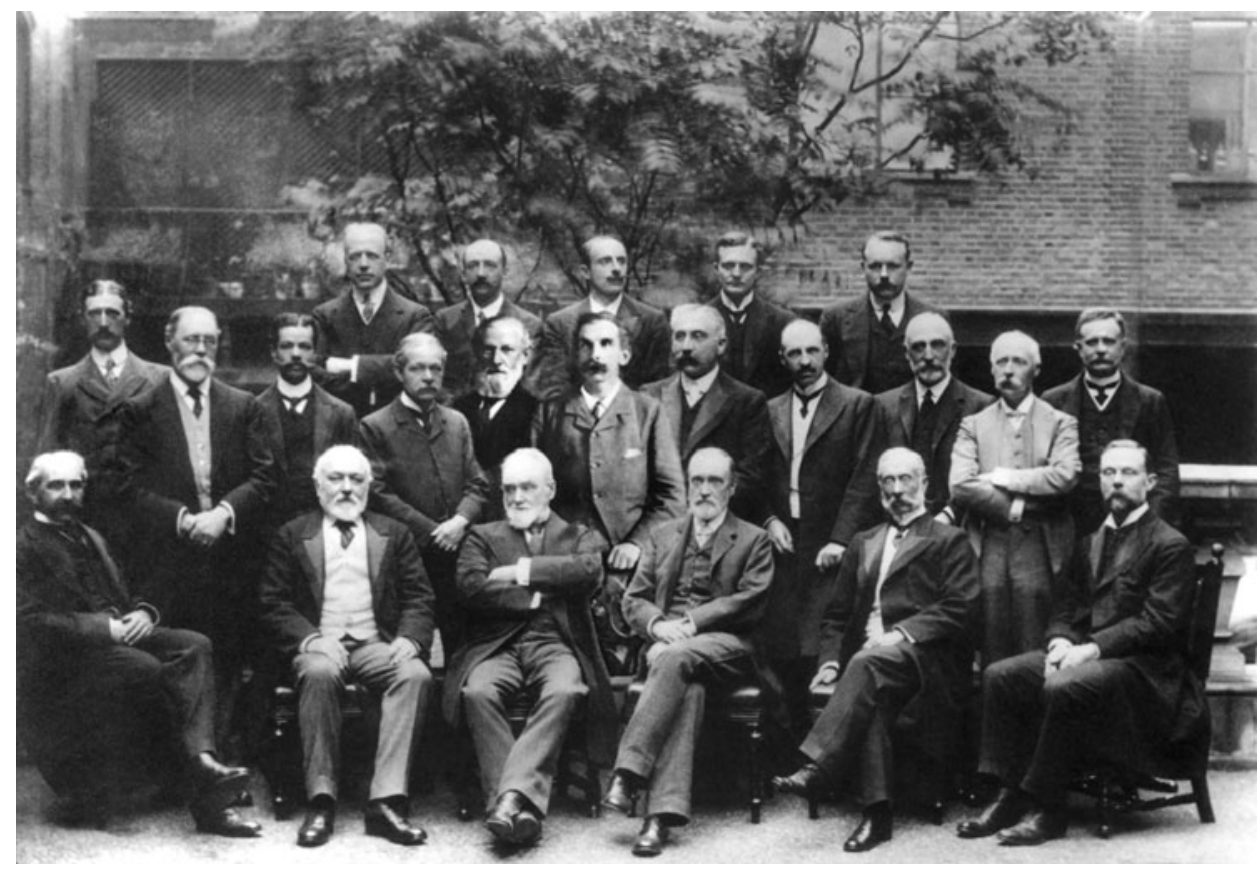

Figure 2: Consultants at Queen Square, 1906. Back row, left to right: Donald John Armour, Frederick Eustace Batten, James Collier, Percy Sargent, Edward Farquhar Buzzard. Middle row, left to right: Walter Tate, Charles Edward Beevor, James Samuel Risien Russell, Alphonso Elkin Cumberbatch, William Richard Gowers, Victor Alexander Haden Horsley, Charles Alfred Ballance, William Aldren Turner, James Taylor, Marcus Gunn, Howard Henry Tooth. Front row, left to right: Felix Semon, Thomas Buzzard, John Hughlings Jackson, Henry Charlton Bastian, David Ferrier, Joseph Arderne Ormerod; Gordon Holmes was appointed consultant in 1909; Queen Square Archives, QSA/880.

and he had a reputation of being 'unsympathetic towards soldiers with shell shock' ${ }^{57}$ Rejected by the Royal Army Medical Corps at the beginning of the war because of his poor eyesight, he joined Percy Sargent, a surgeon at Queen Square, at a Red Cross Hospital in France. There Holmes treated soldiers with brain and spinal trauma. In view of the urgent demand for doctors, his fitness was reconsidered and Holmes was eventually appointed consulting neurologist to the British Expeditionary Force in France. ${ }^{58}$ As British soldiers were not issued with helmets until 1916, he had a constant supply of case material and published extensively on injuries of the spinal cord, the cerebellum and the visual cortex. ${ }^{59}$ Holmes' clinical career was advanced significantly by his wartime practice and he served as editor of Brain from 1922 to 1937.

57 Ian McDonald, 'Gordon Holmes Lecture: Gordon Holmes and the Neurological Heritage', Brain, 130, 1 (2007), 288-98: 295. Holmes openly admitted that he had mainly seen the 'psychoneuroses' as a source of income in peace-times, as cited in Myers, op. cit. (note 8), 20.

58 Ibid.

59 Gordon Holmes, 'The Goulstonian Lectures on Spinal Injuries of Warfare: Delivered before the Royal College of Physicians of London', BMJ, 2, 2867 (1915), 855-61; Gordon Holmes, 'Disturbances of Vision by Cerebral Lesions', British Journal of Ophthalmology, 2,7 (1918), 353-84; Gordon Holmes and W.T. Lister, 'Disturbances of Vision from Cerebral Lesions, with Special Reference to the Cortical Representation of the Macula', Brain, 39, (1916), 34-73, Percy Sargent and Gordon Holmes, 'Preliminary Notes on the Treatment of the Cranial Injuries of Warfare', BMJ, 1, 2830 (1915), 537-41. 
Howard H. Tooth (1852-1925) was described by Holmes as 'careful and conscientious in the care of his patients and an excellent teacher' ${ }^{60}$ During the Boer War, he had worked in a large base hospital in South Africa. Having gained experience of post-combat disorders, most military patients with functional neurological disorders referred to Queen Square during the first two years of the war came under Tooth's care. However, he was then appointed as a consulting physician to British forces in the Near East, which significantly reduced his clinical time at the National Hospital (only seven of his eighty-four patients were 1917/18 admissions). His notes demonstrate his conscientiousness and high attention to detail.

In January 1916, Frederick Eustace Batten (1865-1918), pathologist at the National Hospital from 1889 and honorary physician and Dean of its Medical School from 1900, published an article on soldiers with functional disorders admitted to the hospital between January and November 1915. ${ }^{61}$ Yealland might have been inspired by Batten's case histories and treatment descriptions when he wrote his book on Hysterical Disorders of Warfare in $1918 .^{62}$ In contrast to his junior colleague Yealland, Batten covered in great detail 'the patient's mental attitude'. ${ }^{63}$ For example, he discussed loss of memory and psychotic phenomena in response to the war trauma in his 1916 article. However, contemporaries observed 'a consistent aloofness to psychological phenomena' in his demeanour. ${ }^{64}$ Unlike Yealland, Batten presented no consistent treatment concept and he openly admitted that his treatment outcomes were disappointing.

William Aldren Turner (1864-1945), as a Territorial officer in the Royal Army Medical Corps had been rushed to France in December 1914 as a temporary lieutenant colonel when it became clear that 'nervous and mental shock' casualties were multiplying. He was one of the few doctors at the National Hospital with first-hand experience of casualties in France. As a consultant both at King's College Hospital and the National Hospital, he was responsible for devising a management strategy for shell shock and in January 1915 was appointed consultant neurologist to the War Office. Although he wrote several articles on psychological casualties and treated a considerable number of soldiers with functional neurological disorders at the National Hospital, ${ }^{65}$ he did not publish any Queen Square case histories. After the war, he remained adviser on neurology to the War office and later to the Ministry of Pensions. ${ }^{66}$

\footnotetext{
${ }^{60}$ Holmes, op. cit. (note 38), 51.

${ }^{61}$ Frederick Eustace Batten, 'Some Functional Nervous Affections Produced by the War', The Quarterly Journal of Medicine , 9, 34 (1916), 73-82. We were able to identify all case histories Batten chose for his article among the Queen Square case records. Batten provided the patients' initials and he literally cited whole passages from the case record. Most of his cases had been treated by his colleague Tooth.

${ }^{62}$ Lewis Ralph Yealland, Hysterical Disorders of Warfare (London: MacMillan, 1918). For a more detailed description of Yealland's work see Linden, Jones, and Lees, op. cit. (note 23). Yealland's cases were admitted between May 1916 and January 1918.

63 Batten, op. cit. (note 61), 73.

64 W.J.M.A. Maloney, 'Obituary: “The National” and Dr F.E. Batten', Journal of Nervous and Mental Disease, 49, 1 (1919), 91-4: 92-3.

65 Turner, op. cit. (note 1); William Aldren Turner, 'Nervous and Mental Shock', BMJ, 1, 2893 (1916), 830-2; William Aldren Turner, 'The Bradshaw Lecture on Neuroses and Psychoses of War: Delivered before the Royal College of Physicians of London on November 7th, 1918', The Lancet, 192, 4967 (1918), 613-17.

${ }^{66}$ Holmes, op. cit. (note 38), 64.
} 


\section{The Soldier-Patients of Queen Square}

The 462 soldiers with functional neurological symptoms provided the material for our analysis (see Table 1). In 1914, only five soldiers with functional disorders were admitted to Queen Square, the numbers rising to 122 in 1915 and 121 in 1916 before falling to 94 in 1917 and 87 in 1918, while in 1919 there were only 33 new military in-patients with functional disorders. The vast majority were private soldiers $(83 \%) ; 16 \%$ were noncommissioned officers (ranks of lance corporal, corporal, sergeant and sergeant major). This distribution is similar to that in the forward psychiatric centres where $83 \%$ of patients were private soldiers, $11.7 \%$ corporals and $4.48 \%$ sergeants and warrant officers. ${ }^{67}$ Only four officers with functional disorders were admitted to Queen Square during the war years, which is lower than would be expected given their distribution in the army (about one to thirty men), but can be explained by the provision of treatment specifically for officers, for example at Golders Green, North London. In addition, consultants at Queen Square saw outpatients with war trauma on a private basis, none of whose records have survived), and, given their ability to pay, there may have been a higher proportion of officers amongst this group.

Most soldiers were British, but there were also Irish, Belgian, Canadian and South African servicemen. On average they had developed their symptoms nine months before admission to Queen Square. The mean age on admission was twenty-eight years. The youngest referral was seventeen, while the oldest was sixty years. The average length of stay in hospital for soldiers with functional disorders was sixty-nine days, exceeding the fifty-three days of average treatment duration before the war. Of the 462 soldiers studied, 433 had been involved in front-line service, but 29 soldiers developed functional disorders without even having been exposed to combat. Our analysis of German case records ${ }^{68}$ revealed a similar phenomenon. Here, too, it appeared that the anticipation of danger could trigger similar processes as actual threat. Of the soldiers who were treated for functional disorders, 119 also had physical wounds.

The international reputation of the hospital was illustrated by the case of George C., a 25-year-old private from the Australian Infantry who was admitted to Queen Square on 22 October 1915 having been invalided from Gallipoli. He had been transported to Egypt on a hospital ship where he was treated at the 21st General Hospital in Alexandria. George C. gave a hand-written account of his efforts to obtain a transfer to the National Hospital for treatment:

\footnotetext{
When in the 21st General Hospital Alexandria Egypt I was ordered home to Australia . . . And was told that so many had gone there [to Queen Square] that they were only sending curable cases there and as mine would be a very long time I would have to go to Australia. But if I wanted to get to England I had to sign to the effect that if I was not cured within three months, I would have to pay my fare back to Australia because I came here on my own decision as the Board had decided to send me to Australia. Anyhow I thought it would give myself a chance as so many had got back their voice in England and I had not been home for five years. So I chanced paying my own fare anyhow whatever happening and now I have wrote to Commissioner of Australia Sir George Reid, and he informed me that all would be well with me whatever happened.
}

I came to England on the Glengorm Castle to Southampton I believe and then to Camberwell Hospital. I had a coughing for a night or two and since then I have been a bit mixed. I have not spoken a word since I have been in England but one of my mates told me I said three words in Alexandria but over excited myself and the doctor said

67 Edgar Jones, Adam Thomas and Stephen Ironside, 'Shell Shock: An Outcome Study of a First World War "PIE” Unit', Psychological Medicine, 37, 2 (2007), 215-23.

68 Stefanie Caroline Linden, Volker Hess and Edgar Jones, 'The Neurological Manifestations of Trauma: Lessons from World War I’, European Archives of Psychiatry and Clinical Neuroscience, 262, 3 (2012), $253-64$. 
it would be alright in a few days. By all accounts I could not cough or whistle but now I do both. And also since I have had a cough I have been able to whisper .... I was under treatment by another doctor here somewhere which have seemed done me a little good. ${ }^{69}$

This soldier was discharged from the National Hospital as 'cured'.

\section{Symptoms}

The symptoms of traumatised soldiers were diverse and could affect every system of the body (Table 1). British medical journals of the war years were filled with reports of the common functional syndromes, such as disordered action of the heart but also recorded less common functional phenomena such as the 'Big Belly' or 'les gros ventres de la guerre' in French soldiers, where the abdomen was 'excessively prominent, recalling that of a woman seven or eight months pregnant ${ }^{70}$ or 'miner's nystagmus', a functional disorder with visual disturbances and rhythmic oscillation of the eyes that was known from peacetime coal miners. ${ }^{71}$

Myers believed that there was often a link between the form that a functional somatic disorder took and earlier traumatic experiences, such as accidents. In addition, he argued that the symptoms themselves could reflect the nature of the shocking event; for example, a blaze of light across the eyes leading to functional blindness or an intolerably intense sound leading to deafness without organic cause. Furthermore, Myers hypothesised that some disorders could be a remnant of a stuporous or confused state following an acute shock (for example mutism) or 'the persistent expression of the emotion which ha[d] produced [the] condition' (such as facial tics as expression of horror). ${ }^{72}$

\section{Triggers}

Physicians involved in the treatment of traumatised soldiers documented the circumstances surrounding their patients' breakdown as potential clues to the aetiology of these disorders. The Queen Square records list both physical (for example, injuries obtained during front-line service or being buried alive*) and psychological (for example, witnessing a comrade's death) factors (see Table 2). The physicians' view on the role of shell explosions in a soldier's mental breakdown evolved as the war unfolded. W.H.R. Rivers (1864-1922), who had treated traumatised soldiers at Maghull and Craiglockhart, wrote in the foreword to War Neuroses by John MacCurdy:

In the early days of the war the medical profession ... was inclined to emphasise the physical aspect of the antecedents of a war neurosis. As the war has progressed the physical conception has given way before one which regards the shell explosion or other catastrophe of warfare as, in the vast majority of cases, merely the spark which has released long pent up forces of a psychical kind . . ${ }^{73}$

By 1918, most British doctors had moved away from the idea of an underlying organic lesion caused by the impact of the explosion. The shell explosion was rather seen as part of a complex aetiological model, where physical and psychological triggers interacted. Even the neuropathologist Frederick Walker Mott (1853-1926), who never abandoned the

${ }^{69}$ George C., Queen Square Records, Dr Tooth, 1915, Queen Square Archive; patient's handwritten account attached to case record.

70 'An epitome of current medical literature, "Big Belly” In Soldiers', BMJ, 2, 2961 (1917), 9.

71 Charles F. Harford, 'Visual Neuroses of Miners in their Relation to Military Service', BMJ, 1, 2879 (1916), $340-2$.

${ }^{72}$ Myers, op. cit. (note 8), 70-1.

73 John Thomson MacCurdy, War Neuroses (Cambridge: Cambridge University Press, 1918), V. 


\begin{tabular}{|c|c|c|}
\hline Trauma category & Specific trauma & Number of me \\
\hline \multirow[t]{7}{*}{ Physical } & Injury during front-line service & 76 \\
\hline & Burial & 50 \\
\hline & $\begin{array}{l}\text { Accident during construction work } \\
\text { (bridge, dugout etc.) }\end{array}$ & 10 \\
\hline & $\begin{array}{l}\text { Accident with horses (horse fell } \\
\text { on him, kicked soldier, fall from } \\
\text { horse) }\end{array}$ & 8 \\
\hline & Operation & 2 \\
\hline & $\begin{array}{l}\text { Accident during home leave (fell } \\
\text { down underground stairs, stepped } \\
\text { out of bus) }\end{array}$ & 3 \\
\hline & Total physical & 149 \\
\hline \multirow[t]{9}{*}{ Psychological } & Shell explosion (without injury) & 111 \\
\hline & Gas attack & 9 \\
\hline & Prospect of returning to front-line & 5 \\
\hline & Vaccination & 3 \\
\hline & $\begin{array}{l}\text { Trouble at home (wife affair, } \\
\text { children or wife ill) }\end{array}$ & 6 \\
\hline & Witness of comrade's injury/death & 20 \\
\hline & Air raid, Zeppelin raid & 4 \\
\hline & Emergency landing & 2 \\
\hline & Total psychological & 160 \\
\hline \multirow[t]{2}{*}{ Somatic illness } & Flu, syphilis, tuberculosis etc. & 8 \\
\hline & Total somatic illness & \\
\hline
\end{tabular}

Table 2: Cases of soldiers with functional disorders where triggering event was mentioned, $n=327$.

primacy of the organic in the genesis of shell shock, stated in his Chadwick Lecture on 'Mental Hygiene And Shell Shock During And After The War' in the summer of 1917:

Living in trenches or dug-outs, exposed to wet, cold, and often to hunger and thirst, dazed or almost stunned by the unceasing din of the guns, disgusted by foul stenches, by the rats and by insect tortures of flies, fleas, bugs, and lice, the minor horrors of war, when combined with frequent grim and gruesome spectacles of comrades suddenly struck down, mangled, wounded, or dead, the memories of which are constantly recurring and exciting a dread of impending death or of being blown up by a mine and buried alive, together constitute experiences so depressing to the vital resistance of the nervous system, that a time must come when even the strongest man will succumb, and a shell bursting near may produce a sudden loss of consciousness, not by concussion or commotion, but by acting as the 'last straw' on an utterly exhausted nervous system worn out by this stress of trench warfare and want of sleep. ${ }^{74}$

Interestingly, several soldiers who had coped well with life in the trenches, broke down during their home leave. For example, 19-year-old Private Edward C., who had joined the 20th London Regiment soon after war was declared and been involved in heavy fighting on the Western front, was admitted while on leave in London. On 19 January 1917 at home in bed, he was disturbed at seven in the evening by a colossal explosion at a munitions' factory in Silvertown, about half a mile from his home. ${ }^{75}$ Although the detonation killed 73 workers and injured a further 400, Edward C.'s house was undamaged. However, the

74 Frederick Walker Mott, 'The Chadwick Lecture on Mental Hygiene and Shell Shock During and after the War', BMJ, 2, 2950 (1917), 39-42: 39.

75 Silvertown in West Ham, Essex, now part of the London Borough of Newham. 
medical notes state that the patient 'was much upset and jumped out of bed. He began to shake all over and has continued to shake without intermission ever since'. ${ }^{76}$ After admission to the National Hospital his symptoms persisted and doctors recommended him for discharge from the army. In other cases, relatively minor incidents during home leave appeared to have triggered a mental breakdown, such as falling down the stairs at Victoria station or tripping when getting off a London bus. In all these cases of breakdown during home leave, admission to Queen Square had a potentially life-saving function, preventing the return of the soldier to the trenches.

Another trigger not directly related to combat was marital infidelity. Private George H., hospital orderly in France, developed severe anxiety and sleeplessness after having received 'news from England informing him of conjugal infidelity on the part of his wife'. ${ }^{77}$ John L. 'had a great mental shock for on arrival home after four years' absence, his wife was out and he found out shortly afterwards that she had been in misalliance with another man'. John L. developed severe depression with sleeplessness, fatigue, loss of appetite and extreme nervousness. His depression was so severe that he failed to apply for a pension. ${ }^{78}$

\section{Motor and Somato-Sensory Symptoms}

At Queen Square, most soldiers with functional disorders suffered from a combination of motor and somato-sensory symptoms (see Table 1). The majority had paralyses of arms or legs, combined with numbness or an altered sensation in the affected area of the body. The other main group of motor symptoms included involuntary movements in form of shaking, tremor or tics. One example was 27-year-old Rifleman Frank D. who was admitted to Queen Square on 4 May 1915 with a diagnosis of 'functional tremor' and 'neurosis like "dog chorea"'. The case record reads:

Patient is a territorial and went out to France in January; he has been quite well up till a week ago, when on April 26th he was buried under a bomb explosion in the trench. He was not unconscious but dazed and all in a tremble, all his limbs were shaking. He was conscious being carried by his comrades out of the trenches to a 'dugout'. A few hours afterwards he had to cry and he was crying for two days. At the same time his arms began to twitch, very frequently at first. He was transferred to the 12th General Hospital in Rouen and from there here. He has a bad headache since all over the head. ${ }^{79}$

The patient showed 'lightening-like synchronous twitching of both arms with contraction of both pectoral muscles, quite involuntary but less frequent if attention is fixed on something else'. After two weeks he was discharged 'recovered' to a convalescent home.

Another instructive case with abnormal motor function was 23-year-old Scottish private Henry M. from the 18th Hussars who was admitted to Queen Square on 18 June 1915 with a diagnosis of functional facial spasm.

On May 13th [1915] patient was struck by several pieces of shrapnel, on the right hand, forearm, shoulder and on the right side of the nose at its base. He was very dazed, but did not lose consciousness. The wounds healed in a month. About a week after being wounded he was operated on in order that a piece of shrapnel might be removed from his face. On recovering from the anaesthetic he found himself unable to move the right side of his face or to open his mouth. This condition, which is quite painless, has persisted since, and he has not eaten solid food or been able to take out his false teeth. He has been fed through a rubber tube inserted between his teeth.

\footnotetext{
76 Edward C., Queen Square Records, Dr Tooth, 1917, Queen Square Archive.

77 George H., Queen Square Records, Dr Russell, 1915, Queen Square Archive.

78 John L., Queen Square Records, Dr Collier, 1919, Queen Square Archive; correspondence between the National Hospital and the London War Pensions Committee, as attached to the clinical record.

${ }^{79}$ Frank D., Queen Square Records, Dr Tooth, 1915, Queen Square Archive.
} 
In all other respects he feels well ... Patient sits up in bed gasping in a highly alarming manner, with his left face in a strong tonic spasm and his jaws tightly set. All efforts to open his mouth are unavailing, so strong is the contraction of his masseters ... He declares himself unable to breathe unless sitting up, and when made to lie down, his neck is strongly retracted and set and he breathes violently through his clenched teeth and holds his breath for as long as he can, assuming a purple tinge, which is apt to be disconcerting until one is accustomed to it. By the moral aid given by strong faradism [an electric current applied by the physician] and force applied to the jaw, it was possible to remove a filthy set of false teeth. During this performance he uttered piercing shrieks and foamed and his rigidly held arms shook violently. Tears ran from his eyes, and he sweated profusely from his muscular exertion in resisting the attentions, well intended though they were, of the physician. When asked to close his eyes he was able to do, in fact the left eye is half closed in the spasm. All tests reveal good power in both sides of the face. The facial and jaw spasm would seem to be voluntary and due to frank malingering. In the intervals of this grotesque performance he lies back on the pillow, without any dyspnoea, but he induces an apparent difficulty in breathing at will. Examination reveals no organic disease or injury in either nervous or other systems. ${ }^{80}$

Within four weeks of inpatient treatment, this soldier made a 'practically complete recovery'. He was recommended for Home service. This case is noteworthy for several reasons. First, it is one of the very rare Queen Square cases where simulation of symptoms was suspected. Even if presentations seemed bizarre or mannered, the genuineness of these conditions was hardly ever doubted by any of the Queen Square doctors, and not a single patient was discharged with a diagnosis of 'malingering' or simulation. Contemporary publications also stressed the rarity of 'pure malingering ... in the British and French $\operatorname{armies}^{\prime}{ }^{81}$ and the rarity of discussions of malingering in the medical records suggests that this account was not mere propaganda. However, it is also possible that malingerers had been sifted out before reaching Queen Square. Secondly, this is a case where functional motor symptoms were grafted onto physical injuries or following local surgery. Functional contractures and paralyses often occurred 'after leaving France, often after the removal of a splint following surgical treatment for a wound to the limb received there' and could be mistaken for a physical injury. ${ }^{82}$ Thirdly, this case demonstrates the immense suffering psychologically wounded soldiers experienced and the impact the trauma had on everyday life. (See Figure 3)

A great diversity of abnormal, and often bizarre, gait patterns is documented in the Queen Square records and in medical publications of the time ${ }^{83}$ as well as in Arthur Hurst's film on War Neuroses. ${ }^{84}$ To illustrate this diversity of gait disorders, we have chosen five cases of soldiers admitted to Queen Square who presented with abnormal gait patterns:

'He sways but catches himself as if in danger of falling. When walking brings feet down in short jerky very forceful steps. Sways and when walking alone seems to dance'. ${ }^{85}$

'Patient walks with back bent, legs stiff, takes steps more or less on his toes, has to be supported when attempting to walk' ${ }^{86}$

${ }^{80}$ Henry M., Queen Square Records, Dr Tooth, 1915, Queen Square Archive.

${ }^{81}$ Arthur Frederick Hurst, Medical Diseases of the War, 2nd edn. (London: Edward Arnold, 1918), 28-9. Other physicians who emphasised that cases of malingering were exceptional were Mott and Myers: Mott, op. cit. (note 48), 123. Myers, op. cit. (note 8), 40.

82 Myers, op. cit. (note 8), 132.

${ }^{83}$ Frederick Walker Mott, 'The Lettsomian Lectures on the Effects of High Explosives upon the Central Nervous System: Delivered before the Medical Society of London: Lecture III, delivered on March 6th,' The Lancet, 187, 4828 (1916), 545-53: 552.

${ }^{84}$ Edgar Jones, 'War Neuroses and Arthur Hurst: A Pioneering Medical Film About the Treatment of Psychiatric Battle Casualties', Journal of the History of Medicine and Allied Sciences, 67, 3 (2012), 345-73.

85 Harry C., Queen Square Records, Dr Collier, 1917, Queen Square Archive.

${ }^{86}$ Frederick M., Queen Square Records, Dr Buzzard, 1919, Queen Square Archive. 


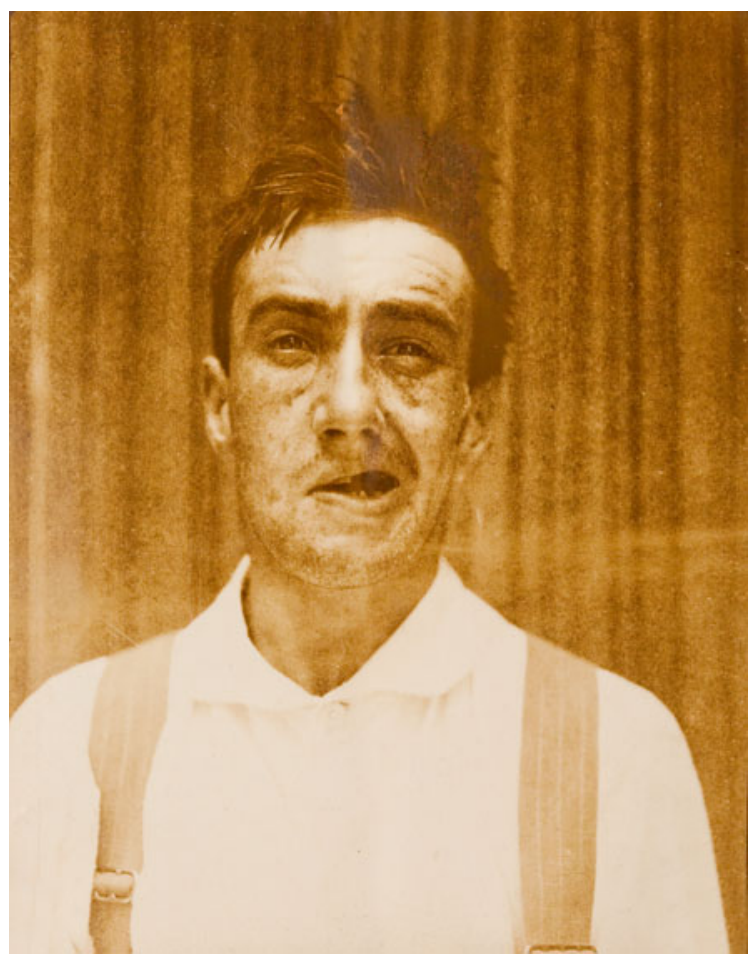

Figure 3: Private Henry M. with functional facial spasm; photograph attached to case record; Henry M., Queen Square Records, Dr Tooth, 1915, Queen Square Archives.

'He walks stiff legged holding his body and back stiff and walking on the toes which are stiff. A very peculiar bizarre sort of gait'. ${ }^{87}$

'Very peculiar functional gait. Patient if placed on his legs becomes very rigid, only the toes rest on the floor, the rest of the body bends backwards and becomes very tremulous. His whole body is in a state of clonus' ${ }^{88}$

'Is typically functional. He walks with his knees crossed in a scissor like fashion. $\mathrm{He}$ can walk without a stick but he is very unsteady'. ${ }^{89}$

The notes record that all five cases responded well to treatment and the servicemen were discharged from hospital able to walk normally. However, no follow-up studies were conducted to establish whether the cure was sustained. This clinical evidence contrasts with the symptom patterns recorded in the war pension files held at TNA. A random sample of two hundred cases of shell shock found that gait abnormalities were rare, though tremor and dizziness were widely reported..$^{90}$ There are three possible explanations for this. First, bizarre movement disorders, as visible symptoms, may have attracted disproportionate attention from doctors. Secondly, as reported in the contemporary literature, gait disorders appeared to respond well to treatment and thus rarely provided a basis for pension

\footnotetext{
${ }^{87}$ Frederick S.M., Queen Square Records, Dr Tooth, 1919, Queen Square Archive.

${ }^{88}$ George C., Queen Square Records, Dr Collier, 1916, Queen Square Archive.

${ }^{89}$ Charles S., Queen Square Records, Dr Steward, 1916, Queen Square Archive.

90 Jones et al., op. cit. (note 25).
} 
claims. Thirdly, cases characterised by a grossly disordered gait could have been rare but were concentrated in specialist neurological units giving the false impression of being widespread.

Other common motor disorders at Queen Square related to the production of speech (see Table 1: sixty-five cases in our sample), either presenting as stuttering/stammering (disordered speech) or a complete inability to talk or even whisper (mutism). Mott was particularly interested in functional speech disorders and he tried to understand why 'these mutes, whose silent thoughts are perfect, [should] be unable to speak? They comprehend all that is said to them unless they are deaf; but it is quite clear that in these cases their internal language is unaffected, for they are able to express their thoughts and judgements perfectly well by writing, even if they are deaf. [...] Many who are unable to speak voluntarily yet call out in their dreams expressions they have used in trench warfare and battle. ${ }^{91}$ Although Mott stopped short of an interpretation in terms of psychological defence mechanisms, he emphasised the symbolic meaning of functional symptoms. The patient was 'paralysed by fear' or 'dumb with fear'. In his aetiological model, tics were 'the result of perseveration of the startling and dodging reflexes, and some of the choreiform movements ... due to perseveration of gesture movements of horror' ${ }^{92}$

\section{Non-Epileptic Seizures}

Non-epileptic seizures occurred in about $7 \%$ of all non-organic cases (without confirmed traumatic lesion or other brain disease) of soldiers admitted to Queen Square. Hysterical seizures proved to be highly 'contagious', as illustrated in one case record of 29-year-old ex-soldier William Charles L. who was admitted to the Queen Square Annex on 31 July 1919. William Charles L. had had his first fit five months previously when he

saw a discharged soldier in a fit while in street, and went to his aid. When the man recovered patient himself had one (his first) which he was told lasted about $1 / 2$ hour. Remembers nothing as to an aura or condition during fit was told he was quite unconscious and was talking and swearing about the Germans. He was able to walk home after but as in subsequent fits felt rather giddy and sick. Next fit occurred a week later while at a music hall at which reference to Germans was being made. Lasted over an hour but could walk home slowly after it. Since then they have become more frequent sometimes having as many as 3 or 4 a day. ${ }^{93}$

This patient continued to have fits during his hospital stay, sometimes lasting between four and five hours. His fits were characterised by struggling and 'talking nonsense, normally about Germans'. He was finally discharged 'in status quo'.

The contagious nature of psychogenic fits was discussed widely in the German literature, as such seizures seem to have been more frequent. ${ }^{94}$ The analysis of the medical literature of the time supports the impression that this group of functional symptoms was not particularly prominent in Britain. For example, Lieutenant Colonel Dudley Carmalt Jones only identified three cases of 'violent hysterical fits' among his 1300 cases of warrelated functional disorders treated at a specialist shell shock unit in France, ${ }^{95}$ and we have not come across any papers specifically dedicated to functional seizures in the British medical literature.

\footnotetext{
91 Mott, op. cit. (note 48), 99.

92 Ibid., 71, 159, 121.

93 William Charles L., Queen Square Records, Dr Tooth, 1919, Queen Square Archive.

94 Max Rohde, 'Neurologische Betrachtungen eines Truppenarztes im Felde', Zeitschrift für die gesamte Neurologie und Psychiatrie, 29 (1915), 379-415.

95 Dudley William Carmalt Jones, 'War-Neurasthenia, Acute and Chronic', Brain, 42 (1919), 171-213.
} 


\section{Sensory Disorders}

Sensory disorders such as functional deafness or functional blindness were comparatively rare among the Queen Square admissions. Arthur Hurst, in charge of a neurological ward at Netley, was convinced that these disorders were primarily a problem of inattention.

Hearing necessitates listening; inattention during a dull sermon results in total deafness to the sermon. In hysterical deafness the patient is so convinced that he cannot hear that he does not listen. Although the sound vibrations reach the ear in the normal way, they do not give rise to the slightest auditory sensation because of this inattention ... Just as one must listen in order to hear, so one must look in order to see, and a man who for any reason is convinced that he is blind fails to see because he does not look. ${ }^{96}$

These descriptions broadly conform to Yealland's ideas and also Janet's model of narrowing of attention or 'contraction of the field of consciousness'. ${ }^{97}$ Queen Square neurologists embraced psychological illness models, as evidenced by the frequent reference to psychological triggers (for example the death of comrades) in the medical records. However, unlike Rivers ${ }^{98}$ and Myers, ${ }^{99}$ they did not explore the meaning and protective nature of these symptoms. Furthermore, their treatment approach focused very much on the symptoms rather than on any underlying trauma.

\section{Autonomic Dysfunction}

Pain and autonomic dysfunction were often part of the clinical picture (see Table 1). Autonomic dysfunction most commonly affected the cardio-respiratory system (with palpitations, shortness of breath, fainting, pericardial pressure), followed by the gastrointestinal system (with nausea, diarrhoea, bloating) and - less frequently documented - the genito-urinary tract (with incontinence of urine and urgency). The following characteristic case with multiple functional somatic symptoms and hypochondriacal ideas was admitted to Queen Square on 3 March 1916 with a diagnosis of 'neurasthenia'. The 23-year-old private Albert R. from the 18th Middlesex Regiment, a miner in civil life, complained about twitching across the temples, a 'feeling of worms crawling in the lower part of the abdomen', shortness of breath, dizzy spells, sleeplessness, weakness and a 'feeling of choking' in his throat. He had developed symptoms after a shell explosion in the trenches in June 1915. When admitted to Queen Square he had

marked twitching of the face and the whole body at times trembles, he looks ill and regurgitates wind. He complains of a peculiar feeling of worms growing in the lower part of the abdomen. He coughs considerably and says that his stomach swells up. A lump appears in his throat which chokes him, and he is continually expectorating. The nights are particularly hard on him, he sits up in bed and has great difficulty in breathing. Cannot lie down properly, but lies over to one side, either the right or the left. Puts his hand up to hold his head still from shaking. He has a depressed sullen look. There are involuntary movements characterised by a very fine tremor manifested when his hands are spread out and his fingers separated. There is a slight tremor in the legs of the same nature as appears in the other part of the body. ${ }^{100}$

The use of chemical weapons from April 1915 introduced a new dimension of threat to trench warfare. Gas had an enduring psychological effect on soldiers whose symptoms often mimicked those of mild exposure to gas but could also be dominated by anxiety,

\footnotetext{
96 Hurst, op. cit. (note 81), 122.

97 Pierre Janet, The Major Symptoms of Hysteria: Fifteen Lectures Given in the Medical School of Harvard University, 2nd edn. (New York: Macmillan, 1920); also discussed in Linden, Jones, and Lees, op. cit. (note 23).

98 W.H.R. Rivers, 'An Address on the Repression of War Experience', The Lancet, 191, 4927 (1918), 173-7.

${ }^{99}$ Charles Samuel Myers, 'Contributions to the Study of Shell Shock: Being an Account of Certain Disorders of Speech, with Special Reference to their Causation and their Relation to Malingering', The Lancet, 188, 4854 (1916), 461-8.

100 Albert R., Queen Square Records, Dr Turner, 1916, Queen Square Archive.
} 
fears, sleep difficulties, dizziness and tremor. ${ }^{101}$ These symptoms applied to several soldiers admitted to Queen Square who had been exposed to gas and elaborately described its devastating effects:

On 5 May 1915, he was overcome by gases sent over by the enemy. Patient was not quite unconscious from the gases. He knew that he was being transported and had an indistinct idea of what was happening around him. At first the gases caused a severe smarting sensation in the eyes, then irritated the mucous membranes of the respiratory tract, causing severe sneezing and coughing. This was followed by severe difficulty in breathing. He made violent efforts to inhale, at the same time there was a feeling of intense and painful irritation in the abdomen, causing sickness, violent retching and severe tenderness so that he felt as though his abdominal organs were being torn from him. Drinking water made the symptoms worse. He got most relief by holding the trunk erect. He noticed that the patients who moved about got most relief. He was transported to Boulogne, arriving May 6; about May 12, he was sent to Rouen. About a week after his arrival in Rouen he began to feel free from the effects of the gas poisoning; but he felt very weak generally; he had frequent attacks of severe giddiness; he was very shaky in all his limbs. He had no ambition to do anything; in fact he could not bring himself to any sustained effort. He was sent from Rouen to England on 5 June 1915, arriving at the National Hospital on 6 June 1915. Pat. believes that his condition had not improved while at Rouen. While in Rouen he received no treatment and was allowed to be up and about as he would. While in Rouen there were days when he felt really fit and well, then he would suddenly be taken with attacks of giddiness and general malaise. Sleep was poor. ${ }^{102}$

\section{Psychological Symptoms}

It is evident from the last case that patients not only presented with classical neurological deficit syndromes and somatisation, but also frequently exhibited psychological symptoms. Common symptoms described in the Queen Square records included irritability, difficulty sleeping and increased sensitivity to noise. These symptoms, which resemble the increased arousal cluster of today's post-traumatic stress disorder patients, were reported as being common to almost all soldiers who had been through traumatic experiences. ${ }^{103}$ These 'subjective' disturbances, which could be easily overlooked in a cursory examination, could cause considerable suffering and 'make life for some of their victims a veritable hell'. ${ }^{104}$

Soldiers with severe depression were rarely seen at Queen Square because they were referred to specialised mental hospitals. ${ }^{105}$ Similarly, psychotic symptoms were not a common presentation. In the Queen Square records, we identified only one case with auditory and visual hallucinations occurring after a shell explosion in the trenches. ${ }^{106}$ The observation that a large proportion of psychotic and confusional states in soldiers on active service were 'of an eminently recoverable character' led to the passage of the Mental Treatment Bill, which was introduced into the House of Commons by Cecil Harmsworth, the Under Secretary for Home Affairs, on 20 April 1915. This bill removed the necessity

101 Edgar Jones et al., 'Psychological Effects of Chemical Weapons: A Follow-up Study of First World War Veterans', Psychological Medicine, 38, 10 (2008), 1419-26.

102 Harry M., Queen Square Records, Dr Tooth, 1915, Queen Square Archive.

103 Hurst, op. cit. (note 81), 41.

104 Grafton Elliot Smith and Tom Hatherley Pear, Shell Shock and Its Lessons, 2nd edn. (Manchester: Manchester University Press, 1917), 12-3.

105 Turner, 'Nervous and Mental Shock', op. cit. (note 1); for a contemporary analysis of patient populations at specialised mental institutions see R. Eager, 'A Record of Admissions to the Mental Section of the Lord Derby War Hospital, Warrington, from June 17th, 1916, to June 16th, 1917', The Journal of Mental Science, 64 (1918), 272-95 and D.K. Henderson, 'War Psychoses: An Analysis of 202 Cases of Mental Disorder Occurring in Home Troops', The Journal of Mental Science, 64 (1918), 165-89, both for the mental section of the Lord Derby War Hospital near Warrington in Lancashire; for the Dykebar Hospital for mental diseases in Paisley in Scotland, see R.D. Hotchkis, 'Renfrew District Asylum as a War Hospital for Mental Invalids: Some Contrasts in Administration. With an Analysis of Cases Admitted During the First Year', The Journal of Mental Science, 63 (1917), 238-49.

106 Harold D., Queen Square Records, Dr Turner, 1916, Queen Square Archive. 
for formal certification of mental disorders occurring in soldiers during active service and allowed informal treatment for up to six months. ${ }^{107}$

Transient states of altered consciousness with reduced responsiveness, sometimes with aggressive behaviour and re-enactment of battle scenes, occurred in about $5 \%$ of all soldiers admitted to Queen Square with functional disorders. These dream-like states were frequently reported in medical publications during the war years ${ }^{108}$ and bore similarities to the syndrome described as 'terror psychosis' by the German neurologist and psychiatrist Karl Kleist. ${ }^{109}$ Mott, based at the Maudsley Hospital, reported a dreamlike state with disorientation to time and place in which combat scenes were relived, often amounting to vivid imagery and sometimes hallucinations. ${ }^{110}$

During these episodes, patients were reported as being highly anxious and aroused. Aggressive outbursts, ideas of reference and persecution (without taking the form of delusions) as well as misjudgements of the situation were also common. Some of these symptoms, particularly anxiety and hallucinations were more pronounced at night. Patients often startled from their sleep and continued to experience the dream in a subconscious state. After these symptoms of arousal had passed, Queen Square doctors often recorded irritability, jumpiness and amnesia for the traumatic experience. The tendency of the individual exposed to long-lasting adversity to drift into an altered mental state for 'temporary relief' was described by Charles Samuel Myers, in his book Shell Shock in France. ${ }^{111}$ Mott also described dissociative states as a protective mechanism and natural response to trench warfare. ${ }^{112}$

According to Aldren Turner, front-line soldiers also presented with stupor and confusion in acute reaction to fear, horror and commotion. ${ }^{113}$ However, these states could also take a chronic course, as in 26-year-old private Harry D. who was treated for 'shell shock' from 1 July 1916 until 20 February 1917. He had developed a catatonic state:

On admission to the National Hospital it was impossible to obtain any history as to his illness or his past life on account of great mental confusion. When asked a question he looks blank and usually repeats the last word of the sentence, for instance when asked when he went to France he looked vacant, handled his identification disc and repeated the word 'France'. When asked where he lived he was able to say Newcastle but went on repeating it in an aimless way. Cerebration is very slow, when asked if he had any children, he repeated children and after a few seconds said 'Yes'. When asked if he had a headache, he put his hand across his forehead but said nothing. He called a watch a clock; a canary a mouse, and a pen a pick. When left alone he is quite quiet but has a rather strained expression. He looks between 35 and 40 years of age and is going bald. ${ }^{114}$

After ten days of inpatient treatment with isolation, massages and sedatives, Harry D. improved considerably and was then able to give a clearer account of his terrifying experiences at the front. Nevertheless, he never fully recovered and after eight months of inpatient treatment he was recommended for discharge from the army.

107 Saturday, May 1, 1915, 'Nerves and War: The Mental Treatment Bill', The Lancet, 185, 4783 (1915), 919-20.

108 For example by Mott in Mott, op. cit. (note 74) and Mott, op. cit. (note 48), 113, where he calls these states 'hallucinatory mental confusion'; also by Turner in Turner, op. cit. (note 1).

${ }^{109}$ Karl Kleist, 'Schreckpsychosen', Allgemeine Zeitschrift für Psychiatrie und psychisch-gerichtliche Medizin, 74 (1918), 432-510.

110 Mott, op. cit. (note 48), 47-8.

111 Myers, op. cit. (note 8), 70.

112 Mott, op. cit. (note 48), 71.

113 Turner, 'The Bradshaw Lecture', op. cit. (note 65), 613.

${ }^{114}$ Harry D., Queen Square Records, Dr Russell, 1916, Queen Square Archive. 


\section{Changes of Symptoms Over Time}

The Queen Square case records allow us to track changes in the clinical presentation across the war years (see Table 1; each patient could have symptoms from up to four symptom categories). Their relative prevalence changed over time. While motor symptoms (mainly paralyses, but also involuntary movements), somato-sensory disturbances and speech disorders were equally distributed over the war years, cases of anxiety and depression were prominent only during the first two years of the war. This phenomenon probably reflected the development of improved assessment and referral procedures for servicemen invalided to the UK. From 1916 onwards, neuropsychiatric cases invalided from France were sent to the Maudsley Hospital or D Block at Netley for specialist appraisal before being referred for specific treatment so that cases of shell shock manifested primarily by psychological symptoms were no longer referred to Queen Square. These findings contradict Leese's impression that 'in 1915 many of the complaints (of invalided soldiers) were less severe than the fatigue and anxiety cases of 1916 and 1917' ${ }^{115}$ In 1917 and 1918 soldiers admitted to Queen Square were very rarely suffering from mood symptoms (difference statistically significant: Chi-Square, $p<0.005$, pooled for 1915/16 versus 1917/18).

\section{Cultural Influences on Symptoms}

The most striking difference between the Queen Square records and our German patient samples ${ }^{116}$ concerns the incidence of functional seizures. In our Berlin sample, functional seizures were 3.5 times more frequent than at Queen Square $(28 / 100=28 \%$ versus $34 / 462=7 \%$ at Queen Square). This result accords with contemporary medical publications. British journals paid little attention to psychogenic seizures and concentrated on functional disorders concerning the heart and sensory-motor system. Conversely, German psychiatrists and neurologists consistently reported high rates of seizure disorders and conducted numerous studies designed to differentiate between functional seizures and genuine epilepsy. ${ }^{117}$ Jones and Wessely argued that functional somatic syndromes may be particularly prone to cultural forces: 'culture, perhaps, has its greatest opportunity to influence the form of, and meaning attached to, medical disorders when scientific experiment and clinical investigation have failed to define or identify their aetiology'. ${ }^{118}$ In the pre-EEG era, a clear distinction between organic or psychogenic causation in seizure disorders could not be made and doctors had to make their diagnosis on the basis of patient history and clinical observation. Jones and Wessely also thought that doctors were likely to look for and pay attention to symptoms that fell within their specialist area. If the psychiatrists in Berlin and Jena had been specialists in seizure disorders, then this plausibly would have influenced their diagnostic decisions. Furthermore, these centres would have attracted higher referrals of cases characterised by seizure disorders. However, this argument for the higher incidence of functional seizures in Germany is unlikely to

\footnotetext{
115 Leese, op. cit. (note 16), 97.

116 German case records from the Department for Psychiatric and Nervous disorders of the Charité in Berlin and the Jena Military Hospital, for more details see Linden, Hess, and Jones, op. cit. (note 68); Linden and Jones, op. cit. (note 24$)$.

${ }^{117}$ Karl Bonhoeffer, 'Erfahrungen über Epilepsie und Verwandtes im Feldzuge', Monatsschrift für Psychiatrie und Neurologie, 38 (1915), 61-72.

118 Edgar Jones and Simon Wessely, 'War Syndromes: The Impact of Culture on Medically Unexplained Symptoms', Medical History, 49, 1 (2005), 55-78: 56.
} 
provide a full explanation because these factors would have applied at least equally to the National Hospital, a neurological hospital which had a special focus on epilepsy.

In the contemporary medical literature, functional seizures were linked to young soldiers and those of lower social and military status. ${ }^{119}$ Differences in patient populations, therefore, may have accounted for the higher proportions of functional seizures reported in Berlin compared with London. However, as the average age of soldiers in our patient samples was very similar (27.4 \pm 7.1 for Berlin and $27.8 \pm 7.5$ for London) and all institutions mainly cared for the lower ranks (88\% in Berlin and $83 \%$ in London), these factors do not appear to be responsible for the different proportions of functional seizures among military admissions.

Another possible explanation for the low number of functional seizures in the UK may be that British doctors - in keeping with their strong organic orientation - had a tendency to diagnose functional seizures as epilepsy. However, this hypothesis is not supported by a survey of epilepsy cases at Queen Square. Although diagnosis of epileptic seizures was more difficult in the pre-EEG era, the Queen Square doctors were adept at making this distinction, and many of their typical epileptic patients had suffered seizures from early childhood. The case records showed that doctors applied a range of criteria that had to be fulfilled to meet a diagnosis of functional seizure disorder; these included goal-directed ictal limb or eye movements, absence of enuresis, tongue bites and cyanosis or talking during the seizure, ${ }^{120}$ criteria very similar to those employed in Berlin. ${ }^{121}$

While aetiological models revealed only slight differences between Britain and Germany, the medical literature of the time pointed towards more pronounced differences in therapeutic approaches, which could explain the different rates of functional seizures in both countries. However, despite apparent differences in British and German treatment preferences, the management of functional seizure disorders was very similar in both countries. Because of the contagious nature of functional seizures and their tendency to become more prominent with increased attention and compassion the favoured treatment in Britain and Germany was isolation. ${ }^{122}$ Even Yealland, a strong advocate of electrotherapy, did not apply electric currents in this patient group and instead based his treatment on suggestion, re-education and isolation. German isolation therapy was arguably more aggressive - with stricter isolation ('psychische Abstinenzkur') and also confinement to locked wards - but these slight differences in the quality of treatment are unlikely to explain the higher rates of functional seizures at the Charite and in Jena.

We cannot rule out the possibility that functional seizures were more common in British base hospitals in France but not referred to specialised neurological treatment centres to avoid a consolidation of symptoms. This assumption, however, is not supported by published data such as the large study carried out by Carmalt Jones which included 1300 soldiers with functional disorders, among them only three cases with functional seizures. ${ }^{123}$ What might have accounted for the lower numbers of functional seizures at Queen Square could have been an unofficial policy of not treating soldiers with functional seizures or at least not transferring them to home hospitals where symptoms were likely

\footnotetext{
119 Ernst Jolowicz, 'Statistik über 5455 organische und funktionelle Nervenerkrankungen im Kriege: Gesichtet nach Truppenteilen, Dienstgraden, Alter, Dienstzeit, Nationalität und Berufen', Zeitschrift für die gesamte Neurologie und Psychiatrie, 52 (1919), 145-62.

${ }^{120}$ Lewis Ralph Yealland, 'Hysterical Fits, with some Reference to their Treatment', Proceedings of the Royal Society of Medicine, 16 (1923), 85-94.

${ }^{121}$ Linden, Hess, and Jones, op. cit. (note 68).

122 Mott, op. cit. (note 48), 148.

123 Jones, op. cit. (note 95).
} 
to consolidate. Although Myers 'was asked to arrange that epileptic patients should ... not be admitted into neurological centres,' this request was only made in June 1918 and it is not clear how much this impacted on the actual disposal of soldier patients. ${ }^{124}$ It is also highly unlikely that soldiers with functional seizures, who posed a threat to general discipline and order, were kept at the front line. Another possibility is that they might have been imprisoned for disruptive behaviour. Further research into this possibility would involve searching the records of the disciplinary system, for example punishment camps and military prisons.

Differences in institutions, disposal systems, patient populations, aetiological illness models and treatment approaches appear unlikely to have been major confounding factors. If the incidence of functional seizures was significantly lower in British soldiers compared with their German counterparts, then cultural differences had plausibly influenced the expression of post-traumatic reactions in otherwise similar circumstances. The physical expression of distress may be mediated by cultural forces through popular health fears which alert patients and doctors to particular areas of the body. ${ }^{125}$ Multiple investigations have been shown to reinforce symptoms. What public opinion considers acceptable or unacceptable, authentic or false, respectable or shameful also influences the expression of distress. Popular attitudes towards seizures and the role of electricity may have been different in Britain and Germany. Andreas Killen has demonstrated how the rapid rise of electrical industries in Berlin and electrification of many aspects of daily life transformed thinking not just about technology but about society and the human mind. ${ }^{126}$ The influence of the electrical industry, led by Siemens and AEG, set Berlin apart from both London and Paris. ${ }^{127}$ Conceptual links between electricity and epilepsy had already been proposed in the mid-nineteenth century by the anatomist Jacobus Schroeder van der Kolk (1797-1862) in the Netherlands ${ }^{128}$ and by the physician to King's College Hospital, Robert Bentley Todd (1809-1860), in Britain. ${ }^{129}$ However, the first experimental demonstration of this link had to wait until 1914 when the Polish physiologists Cybulski and Jelenska-Macieszyna published a photographic record of changes in electrical activity in the cerebral cortex of a dog during a seizure. ${ }^{130}$ The question of whether these electrophysiological observations had any direct influence on German and British neuropsychiatry of the time - let alone on the public perception of epilepsy - has so far received little attention and research in this area would be needed to assess their cultural relevance.

Our finding that functional seizures were more frequently reported in the case notes of German soldiers than in comparable British records has raised important questions about the way symptoms were identified and interpreted. Culturally determined differences in war syndromes thus support Loughran's model of shell shock as a diagnosis shaped by a specific set of contemporary concerns, knowledge and practices. ${ }^{131}$

\footnotetext{
${ }^{124}$ Myers, op. cit. (note 8), 126.

125 Jones and Wessely, op. cit. (note 118).

126 Andreas Killen, Berlin Electropolis: Shock, Nerves and German Modernity (Berkeley, CA: University of California Press, 2006).

127 Winter and Robert, op. cit. (note 30), 34.

128 Owsei Temkin, The Falling Sickness: The History of Epilepsy from the Greeks to the Beginnings of Modern Neurology (Baltimore: The Johns Hopkins University Press, 1945), 283.

${ }^{129}$ Edward H. Reynolds, 'Jackson, Todd, and the Concept of "Discharge” in Epilepsy', Epilepsia, 48, 11 (2007), 2016-22.

${ }^{130}$ Andrzej Grzybowski and Krzysztof Pietrzak, 'Napoleon Cybulski (1854-1919)', Journal of Neurology, 260 (2013), 2942-3.

${ }^{131}$ Loughran, op. cit. (note 11).
} 


\section{Conclusion}

The Queen Square case records reveal how servicemen who had been diagnosed with functional disorders expressed a rich variety of clinical forms. They offer an insight into the impact of trench warfare on the soldier's mind and how this traumatic experience occupied his thoughts during the day and dominated his dreams at night. Public perception of shell shock focused on certain iconic clinical pictures that were popularised in contemporary medical film and later media adaptations, such as hysterical gait disorder. ${ }^{132}$ Yet the Queen Square cases reveal a much greater range of symptoms. Although physical manifestations were particularly prominent, psychological symptoms were ubiquitous and persistent, causing considerable suffering and long-lasting disability. In relation to the most prominent contemporary account of functional disorders at Queen Square, Yealland's book on hysteria, this study shows that his case reports, albeit accurate, only captured a sub-population of patients. Yealland focused on patients with functional motor symptoms who responded well to electrical treatments, but under-represented both the psychological syndromes and the range of treatments offered at the National Hospital. ${ }^{133}$ While shell shock was one of the few new disease categories added to the diagnostic inventory at the beginning of the war, doctors generally agreed that 'the War ha[d] not produced any new form of mental disease'. ${ }^{134}$ The difference between the conflict and the pre-war period was 'one of frequency rather than of kind', ${ }^{135}$ though symptoms such as nightmares and hallucinations were commonly coloured by experiences in the field. ${ }^{136}$ Like their German colleagues, ${ }^{137}$ British doctors eventually concluded that such cases would not be able to 'stand the strain of active service without relapsing' and should therefore be discharged from their military duties and returned to civil life. ${ }^{138}$

This analysis of case records from the leading neurological institution in Britain, combined with earlier research into an equivalent German hospital, supports the hypothesis that similar traumatic triggers can produce different phenomenological consequences in different cultural settings. ${ }^{139}$ The changing patterns of human responses to traumatic experience and their historical and cultural constraints are still relevant for our approach to traumatic and war-related disorders today.

\footnotetext{
132 Julia Barbara Köhne, Kriegshysteriker: Strategische Bilder und mediale Techniken militärpsychiatrischen Wissens (1914-1920) (Husum: Matthiesen, 2009).

133 Linden, Jones, and Lees, op. cit. (note 23).

134 Smith and Pear, op. cit. (note 104), 24: 'For shell shock has brought us no new symptoms ... '; Harold Wiltshire, 'A Contribution to the Aetiology of Shell Shock', The Lancet, 187, 4842 (1916), 1207-12: 1207; Judson S. Bury, 'Pathology of War Neuroses', The Lancet, 192 (1918), 97-9: 97; MacCurdy, op. cit. (note 73), 87: 'no symptoms described in the war cases ... which have not been well known in times of peace'.

135 Bury, op. cit. (note 134), 97.

136 Hotchkis, op. cit. (note 105), 244; Mott, op. cit. (note 48), 111-12.

${ }^{137}$ Linden, Hess, and Jones, op. cit. (note 68).

138 Mott, op. cit. (note 48), 144. Hurst, op. cit. (note 82), 64. 'A man who has once had a mental breakdown is very unlikely to be able to stand the strain of active service without relapsing ... . [S] uch men should never be allowed to return to military duty.'; also Jones, op. cit. (note 95): 'I doubt if anyone who has once developed it will ever be fit for front-line soldiering within the time limit of any war'.

139 Jones et al., op. cit. (note 25).
} 